\title{
Synbiotic Adjuvant Therapy in Atopic Dermatitis: Our Experience
}

\author{
Rial Prado M.J., ${ }^{1, *}$ and Seoane Rodríguez M. ${ }^{2}$ \\ ${ }^{1}$ Allergy and Clinical Immunology Department; ${ }^{2}$ Pediatrics Department, Xerencia Xestión Integrada A Coruña, \\ A Coruña, Galicia, Spain
}

\begin{abstract}
Background: Atopic dermatitis is a disease with a lot of clinical interest because it is the point of attachment between allergic diseases and autoimmune diseases. Probiotics and synbiotics favor the expression of anti-inflammatory Th1 cytokines which produces therapeutic benefits in patients with atopic dermatitis as revealed by recent meta-analysis.

Material and Method: Six patients ( 3 women and 3 men) suffering from moderate atopic dermatitis aged between 16 and 28 years were treated with Bifidobacterium lactis BS01, Lactobacillus rhamnosus LR05 and prebiotic fructo oligosaccharides $\left(2 \times 10^{9} \mathrm{CFU}\right)$ once daily in a period of four months added to their previously scheduled topical treatment. SCORAD index and atopic dermatitis quality of life test (QoLIAD) prior to treatment and four months after treatment were analyzed.

Results: After 4 months of treatment we objectified clinical improvement by reducing the SCORAD index (average of 6 points) and better results in QoLIAD test in 5 of the 6 patients. Previously scheduled medical treatment remained unchanged and no side effect was observed in any of the patients treated.

Discussion: Most of our patients treated obtained clinical improvement and in quality of life without adverse effects, this fact support the results of recent papers concluding that the use of probiotics in diary clinical practice is a safe coadyuvant and possibly effective in the treatment of atopic dermatitis.
\end{abstract}

Keywords: Atopic dermatitis, synbiotics, probiotics, prebiotics, Th1/Th2.

\section{INTRODUCTION}

Atopic dermatitis is a common skin disease that affects a large percentage of the world's population. Atopy is a special type of hypersensitivity that is associated with asthma, allergic rhinitis, and a chronic dermatitis. Criteria that enable a doctor to diagnose it include the typical appearance and distribution of the skin disease in a patient with a personal or family history of atopy. In atopic dermatitis, the skin becomes extremely itchy and inflamed, causing redness, swelling, vesicle formation, cracking, weeping, crusting, and scaling. In addition, dry skin is a very common complaint in almost all those afflicted with atopic dermatitis.

The World Health Organization's 2001 definition of probiotics is "live micro-organisms which, when administered in adequate amounts, confer a health benefit on the host"; prebiotics are chemicals that induce the growth or activity of microorganisms and synbiotics are the combination of pre and probiotics.

Since the Russian scientist Mechnikov discovered L. bulgaricus [1] in the early twentieth century it has been much progress in the field of probiotics, prebiotics

*Address correspondence to this author at the Allergy and Clinical Immunology Department, Complexo Hospitalario Universitario A Coruña, As Xubias de arriba s/n 15006 A Coruña, Spain; Tel: +0034 9811762 05; Fax: 981178 001; E-mail: manuel.jorge.rial.prado@sergas.es and synbiotics, up to run today as a preventive and therapeutic option in many types of diseases with inflammatory basis [2-6].

The scientific interest in this type of treatment is remarkable considering the exponential growth of clinical trials in this field that can be found in Medline in the last 10 years $[7,8]$.

The hygiene hypothesis, postulated by Strachan $[9,10]$ explain that the decrease exposure to microorganisms in modern societies, results in an innate immunity altered in developing children which favors the appearance of diseases mediated by $\lg \mathrm{E}$. This alteration in innate immunity could change by acting on the intestinal bacterial flora [11]. The intestinal bacterial flora is involved in many immune functions such: reduce the antigenic load, inhibit colonization by pathogenic microorganisms, reduce intestinal permeability, secrete Th1 cytokines, induce Treg cells, production of secretory IgA or decrease the levels of $\lg E$ among others [12-15]. The regulation ratio Th1 / Th2 with the increased production of Treg cells is the immunological rationale for clinical benefit to the use of probiotics in allergic diseases [16]. Treg cells are a subpopulation of $T$ cells which modulate the immune system, maintain tolerance to self-antigens, and abrogate autoimmune disease. These cells generally suppress or downregulate induction and proliferation of effector T cells [17]. 
Atopic dermatitis is caused by an imbalance of Th1, Th2, Th17, Th22 and Treg lymphocytes, leading to an increase of proinflammatory mediators such as IL-4, IL5 and IL-13 Th2 lineage which favor IgE responses and inflammation in the acute phase of the disease [16].

Supplementation with specific probiotic strains in patients with atopic dermatitis produces a regulation balance Th1 / Th2 towards Th1, which decreases and improves skin inflammation [18].

\section{MATERIAL AND METHOD}

Patients of our consultations (three men and three women) aged between 16 and 28 years who were referred by poorly controlled atopic dermatitis were recruited. All these patients had been treated by their doctors with emollients, topical corticosteroids and hygienic measures with suboptimal results. Two of these patients were treated with phototherapy refering poor response.

In our office we performed a SCORAD (Severity SC Oring of Atopic Dermatitis), a test of quality of life in atopic dermatitis (Quality of Life Index for Atopic Dermatitis) (QoLIAD) [19], skin prick tests to pneumoallergens of our area and a detailed medical history.

As therapeutic measures we insisted on the restoration of the skin barrier with emollients, hygienic measures skincare, treatment with medium potency topical corticosteroids and calcineurin inhibitors and adjuvant therapy was started with synbiotics for 4 months. The composition of the synbiotic was Bifidobacterium lactis BS01, Lactobacillus rhamnosus LR05 and fructooligosacarides in a concentration of $2 \times 10^{9}$ colony forming units (CFU) at a dose of one sachet per day with food for four months.

\section{RESULTS}

Before starting treatment we performed a SCORAD to all patients to determine the severity of the dermatitis, obtaining increased income to 40 in six patients (mean of 48 points) and were also conducted test of quality of life (QoLIAD) obtaining an average of 12 points. The results of the skin tests with respiratory allergens were negative in 2 patients, tested positive for $D$. pteronyssinus in 4 patients and two of them also tested positive for $\mathrm{L}$. destructor and grass pollen. These patients have moderate persistent allergic rhinitis due to house dust mites hypersensitivity.
After four months of treatment with synbiotics and without having made any changes in medical treatment, clinical improvement was observed in five of our six patients. They re-ran the test QoLIAD and SCORAD and there was an average reduction of six points in the SCORAD and 4 points in the QoLIAD. In none of the six patients were observed adverse effects attributable to medication. Our study has the limitation of being an observational study of everyday clinical practice, has no control group or a large sample size (only six patients).

\section{DISCUSSION}

The fact that most of our patients obtained clinical improvement without observing adverse effects suggests that treatment with synbiotics in atopic dermatitis, it's safe and effectiveness as well reflect the results of recent clinical studies [2-6].

The population on which action has been taken is homogeneous both in age and demographic characteristics and in the severity of the dermatitis. The fact that most of our patients are sensitized to dust mites is to be atopic patients with allergic rhinitis of the northwest of Spain where sensitization to dust mites is very common.

Regarding the synbiotics treatment in our patients it was used the same dose, and the same probiotic strains in all of them (Bifidobacterium lactis BS01, Lactobacillus rhamnosus LR05 and fructooligosacarides in a concentration of $2 \times 10^{9} \mathrm{CFU}$, one sachet per day for four months).

The results of the meta-analysis of treatment with probiotics in atopic dermatitis are contradictory, due to the heterogeneity of the studies analyzed. In these studies different strains, different dosages are used and the population on which it acts is also inhomogeneous on age or severity. However when STROBE criteria applied for the selection of work to analyze, favorable results are obtained for the use of probiotics in atopic dermatitis [20], as well as our everyday clinical practice study reflects.

\section{REFERENCES}

[1] Lilly DM, Stillwell RH. Probiotics: Growth-promoting Factors Produced by Microorganisms. Science 1965; 147(3659): 747-8.

http://dx.doi.org/10.1126/science.147.3659.747

[2] Isolauri E, Rautava S, Salminen S. Probiotics in the development and treatment of allergic disease. Gastroenterology clinics of North America 2012; 41(4): 74762.

http://dx.doi.org/10.1016/j.gtc.2012.08.007 
[3] Ozdemir O. Various effects of different probiotic strains in allergic disorders: an update from laboratory and clinical data. Clinical and Experimental Immunology 2010; 160(3): 295-304.

http://dx.doi.org/10.1111/j.1365-2249.2010.04109.x

[4] Kim JY, Kwon JH, Ahn SH, Lee SI, Han YS, Choi YO, et al. Effect of probiotic mix (Bifidobacterium bifidum, Bifidobacterium lactis, Lactobacillus acidophilus) in the primary prevention of eczema: a double-blind, randomized, placebo-controlled trial. Pediatr Allergy Immunol 2010; 21(2 Pt 2): e386-93.

http://dx.doi.org/10.1111/j.1399-3038.2009.00958.x

[5] Marlow G, Han DY, Wickens K, Stanley T, Crane J, Mitchell EA, Dekker J, Barthow C, Fitzharris P, Ferguson LR, Morgan AR. Differential effects of two probiotics on the risks of eczema and atopy associated with single nucleotide polymorphisms to Toll-like receptors. Pediatr Allergy Immunol 2015: 26: 262-271. http://dx.doi.org/10.1111/pai.12371

[6] Morgan AR, Han DY, Wickens K, Barthow C, Mitchell EA, Stanley TV, Dekker J, Crane J, Ferguson LR. Clinical \& Experimental Allergy 2014; (44): 1255-1265. http://dx.doi.org/10.1111/cea.12394

[7] Frei R, Akdis M, O'Mahony L. Prebiotics, probiotics, synbiotics, and the immune system: experimental data and clinical evidence. Curr Opin Gastroenterol 2015; 31: 153-158. http://dx.doi.org/10.1097/MOG.0000000000000151

[8] Kuitunen M. Probiotics and prebiotics in preventing food allergy and eczema. Curr Opin Allergy Clin Immunol 2013; 13: $280 \mathrm{e} 6$.

[9] Strachan DP. Prebiotics, probiotics, synbiotics, and the immune system: experimental data and clinical evidence. Thorax 2000; 55(Suppl 1): S2-S10. http://dx.doi.org/10.1136/thorax.55.suppl_1.S2

[10] Frei R, Lauener RP, Crameri R, et al. Microbiota and dietary interactions: an update to the hygiene hypothesis? Allergy 2012; 67: 451-461.

http://dx.doi.org/10.1111/j.1398-9995.2011.02783.x

[11] Karimi K, Kandiah N, Chau J, et al. A Lactobacillus rhamnosus strain induces a heme oxygenase dependent increase in Foxp3fl regulatory T cells. PLoS One 2012; 7: e47556.

http://dx.doi.org/10.1371/journal.pone.0047556
[12] Klaenhammer TR, Kleerebezem M, Kopp MV, Rescigno M. The impact of probiotics and prebiotics on the immune system. Nature Reviews Immunology 2012; 12(10): 728-34. http://dx.doi.org/10.1038/nri3312

[13] Konieczna P, Ferstl R, Ziegler $M$, et al. Immunomodulation by Bifidobacterium infantis 35624 in the murine lamina propria requires retinoic acid-dependent and independent mechanisms. PLoS One 2013; 8: e62617. http://dx.doi.org/10.1371/journal.pone.0062617

[14] Konieczna $P$, Groeger D, Ziegler $M$, et al. Bifidobacterium infantis 35624 administration induces Foxp3 $\mathrm{T}$ regulatory cells in human peripheral blood: potential role for myeloid and plasmacytoid dendritic cells. Gut 2012; 61: 354-366. http://dx.doi.org/10.1136/gutjnl-2011-300936

[15] Shanahan F, Quigley EM. Manipulation of the microbiota for treatment of IBS and IBD-challenges and controversies. Gastroenterology 2014; 146: 1554-1563. http://dx.doi.org/10.1053/j.gastro.2014.01.050

[16] Eyerich K, Novak N. Immunology of atopic eczema: overcoming the Th1/Th2 paradigm. Allergy 2013; 68: 974-82. http://dx.doi.org/10.1111/all.12184

[17] Haribhai D, Williams JB, Jia S, et al. A requisite role for induced regulatory $T$ cells in tolerance based on expanding antigen receptor diversity. Immunity 2011; 35(1): 109-2. http://dx.doi.org/10.1016/j.immuni.2011.03.029

[18] Ashram R, Shan NP. Immune system stimulation by probiotic microorganisms. Crit Rev Food Sci Nutr 2014; 54: 938-56. http://dx.doi.org/10.1080/10408398.2011.619671

[19] Whalley D, McKenna SP, Dewar AL, Erdman RA, Kohlmann T, Niero M, Cook SA, Crickx B, Herdman MJ, Frech F, Van Assche D. A new instrument for assessing quality of life in atopic dermatitis: international development of the Quality of Life Index for Atopic Dermatitis (QoLIAD). $\mathrm{Br} \mathrm{J}$ Dermatol 2004; 150(2): 274-83. http://dx.doi.org/10.1111/j.1365-2133.2004.05783.x

[20] da Costa Baptista IP, Accioly E, de Carvalho Padilha P. Effect of the use of probiotics in the treatment of children with atopic dermatitis; a literature review. Nutr Hosp 2013; 28(1): 16-26.

\section{DOI: http://dx.doi.org/10.6000/1927-5951.2016.06.03.2}

(c) 2016 Rial and Seoane; Licensee Lifescience Global.

This is an open access article licensed under the terms of the Creative Commons Attribution Non-Commercial License (http://creativecommons.org/licenses/by-nc/3.0/) which permits unrestricted, non-commercial use, distribution and reproduction in any medium, provided the work is properly cited. 